\title{
EXTENSÃO UNIVERSITÁRIA, ECONOMIA SOLIDÁRIA E GERAÇÃO DE OPORTUNIDADES NO CONTEXTO DA COVID-19: UMA VISÃO A PARTIR DE TRÊS EXPERIÊNCIAS CONCRETAS NO TERRITÓRIO BRASILEIRO'
}

\author{
Sandro Pereira Silva ${ }^{2}$ \\ Clovis Vailant ${ }^{3}$ \\ Oscar Zala Sampaio Neto ${ }^{4}$ \\ Bruna Nunes da Cunha ${ }^{5}$ \\ Solène Tricaud ${ }^{6}$ \\ Frederico Campos Pereira ${ }^{7}$ \\ Lucyana Xavier Azevedo 8 \\ Manoel Pereira de Macêdo Neto ${ }^{9}$ \\ Lício Romero Costa ${ }^{10}$ \\ Adriana Rodrigues da Silva"11 \\ Leandro Pereira Morais ${ }^{12}$ \\ Sérgio Azevedo Fonseca ${ }^{13}$ \\ Caio Luís Chiarello ${ }^{14}$
}

\section{INTRODUÇÃO}

O recente cenário de expansão epidêmica em nível global, provocada pelo novo coronavírus (Covid-19), trouxe à tona uma avassaladora crise humanitária que vai além da questão sanitária propriamente dita, marcada pelo crescente número de vítimas em todo o mundo, afetando também as economias nacionais. Com isso, houve uma elevaçáo do desemprego em todos os países afetados, em virtude das medidas de isolamento indicadas como forma de conter a proliferação viral.

1. DOI: http://dx.doi.org/10.38116/bmt69/economiasolidaria1

2. Técnico de planejamento e pesquisa na Diretoria de Estudos e Políticas Sociais (Disoc) do Ipea. E-mail: <sandro.pereira@ipea.gov.br>.

3. Pesquisador associado da Universidade Federal de Mato Grosso (UFMT).E-mail:<vailantc@hotmail.com>.

4. Professor da UFMT. E-mail:<oscarsampaio@ufmt.br>.

5. Pesquisadora associada da UFMT.E-mail: <bruna.ncunha@gmail.com>.

6. Pesquisadora associada da UFMT.E-mail: <solene.tricaud@gmail.com>.

7. Professor do Instituto Federal de Educação, Ciência e Tecnologia da Paraíba (IFPB), campus Pedras de Fogo. E-mail: $<$ frederico.pereira@ifpb.edu.br>.

8. Professora do IFPB, campus Pedras de Fogo.E-mail: <contato.luazevedo@gmail.com>.

9. Professor do IFPB, campus Cabedelo.E-mail:<manoel.macedo@ifpb.edu.br>.

10. Professor do IFPB, campus Cabedelo.E-mail: <licio.costa@ifpb.edu.br>.

11. Aluna do curso Agente Comunitário de Saúde do IFPB, campus Pedras de Fogo. E-mail: <adriana.silva@academico.ifpb.edu.br>.

12. Professor da Universidade Estadual Paulista (Unesp).E-mail: <lpmorais@gmail.com>.

13. Professor da Unesp. E-mail: <sergio.fonseca@unesp.br>.

14. Pós-doutorando da Unesp.E-mail:<caiomudo@gmail.com>. 
Especificamente no Brasil, dados recentes indicam que, somente no mês de maio, 9,7 milhóes de pessoas perderam suas ocupações, elevando bruscamente o contingente populacional em situaçáo de vulnerabilidade e incerteza econômica. Algumas previsões já apontam para uma queda superior aos 10\% no produto interno bruto (PIB) do país em 2020, o que resultaria em uma situação sem precedentes até então (Dweck et al., 2020). Por sua vez, as políticas públicas de enfrentamento anunciadas até o momento pelo governo federal são controversas, além de serem consideradas tímidas em relação a medidas tomadas por outros países (Nogueira, Silva e Carvalho, 2020; Amitrano et al., 2020; Dieese, 2020; Palludeto et al., 2020; Valadares et al., 2020).

Dado esse contexto emergencial, novas estratégias precisam ser consideradas como possibilidades de geração de oportunidades que auxiliem grupos sociais mais expostos à vulnerabilidade econômica. Instituiçôes públicas, como universidades e institutos de educação tecnológica, tanto de natureza federal quanto estadual, surgem, então, como agentes importantes nesse processo, sobretudo devido à sua capilaridade no território nacional.

Além de seu papel fundamental no desenvolvimento de pesquisas para o desenvolvimento de tratamentos e proteção contra os malefícios sanitários da epidemia, sua atuação nas comunidades, por meio de projetos de extensão, pode auxiliar também grupos sociais a promover atividades produtivas para a geração de trabalho e renda a um contingente considerável de famílias. Nesse sentido, a prática de extensão universitária expressa um vínculo fundamental da universidade com o território e a sociedade em que ela se insere, e é necessariamente indissociável das funções de ensino e pesquisa.

Para esse tipo de atuação, os princípios da economia solidária surgem como orientadores importantes da prática extensionista nesses grupos, com o objetivo de fomentar iniciativas econômicas baseadas no associativismo, na autogestão e no desenvolvimento local sustentável (Silva, 2017). Embora práticas com essa perspectiva já ocorram há algum tempo em grande parte do país, ${ }^{15}$ o cenário de epidemia lançou novos desafios às equipes de extensionistas, que vêm necessitando adequar abordagens metodológicas para o atendimento dessas demandas emergentes que têm se colocado.

Este texto visa, então, divulgar experiências que se encaixam de alguma forma nessa perspectiva, englobando a atuação extensionista de três instituiçóes de educação superior e tecnológica no Brasil - Universidade Federal de Mato Grosso (UFMT), Instituto Federal de Educação, Ciência e Tecnologia da Paraíba (IFPB) e Universidade Estadual Paulista (Unesp). Em geral, tais experiências envolvem a mobilização de grupos associativistas e a construção de novas parcerias, inclusive com os poderes públicos locais, seja para fomentar novas oportunidades de atuação produtiva a partir de demandas específicas de combate à epidemia, seja para assessorar grupos já formados para se adequarem às novas dinâmicas de comercializaçáo em tempos de isolamento social, sem deixarem de se ater a outras necessidades emergenciais que afetam as populaçóes envolvidas. ${ }^{16}$

15. Ver Perissé et al. (2017).

16. Para outras experiências de relação entre extensão universitária e economia solidária no contexto de pandemia, ver 0 artigo $A s$ incubadoras universitárias de economia solidária durante a pandemia: relato de ações da INCUBES/UFPB e da INCUBACOOP/UFRPE, de Benzaquen, Carneiro e Sardá, nesta mesma edição do periódico Mercado de Trabalho: conjuntura e análise. 


\section{A EXTENSÃO UNIVERSITÁRIA ORIENTADA À ECONOMIA SOLIDÁRIA}

As instituiçôes universitárias no Brasil possuem um leque bastante amplo de interações com a dinâmica social em geral, fundamentadas no chamado "tripé" ensino, pesquisa e extensão. Dessa tríade funcional, a ação de extensão consiste no mecanismo pelo qual a comunidade acadêmica se comunica e intervém nas comunidades de seu entorno para além das formas tradicionais de inserção. Ela se desenvolve a partir de projetos nas mais diversas áreas do saber, com o intuito de aplicar e disseminar determinados conhecimentos ou capacidades instaladas nos institutos, envolvendo a participação de professores, estudantes e outros profissionais.

Nas últimas duas décadas, a economia solidária tem se consolidado como um canal importante para a orientação de projetos extensionistas, voltados a auxiliar grupos produtivos e organizações sociais para a geração de trabalho e renda na perspectiva do associativismo e da autogestão, sobretudo em territórios com maiores índices de vulnerabilidade. Essa prática, vale ressaltar, também é indissociável do ensino e da pesquisa, pois parte de situaçóes e demandas concretas e mobiliza diversas capacidades para a busca de soluçôes, permitindo a abertura de horizontes inesgotáveis de aprendizado entre os atores envolvidos, para dentro e para fora dos limites dos campi universitários. Ou seja, a prática extensionista em empreendimentos coletivos que demandam conhecimento técnico para o enfrentamento de problemas cotidianos concretos permite uma interação de conhecimentos e saberes que flui nas duas direçôes, enfatizando uma relação dialética de ensino-aprendizagem (Culti, 2011).

Por sua vez, a extensão universitária sob o paradigma da economia solidária se desenvolve sob distintos referenciais metodológicos, tanto na definiçáo da forma como se constrói essa interação quanto na elaboração dos objetivos e dos próprios limites inerentes à sua prática. Nesse sentido, a orientação para a autonomia dos grupos assessorados e a construção de parcerias duráveis de apoio tornam-se imprescindíveis para a potencializaçáo dos resultados (Addor e Laricchia, 2018).

No caso específico dos empreendimentos de economia solidária (EES), baseados nos princípios da cooperação e da coletividade, esse assessoramento surge no intuito de construir técnicas, instrumentos e metodologias que sirvam para melhorar a estruturação de seus processos de produção, gestão e comercialização, pensando tanto no aumento da produtividade e da renda quanto na melhoria das condiçóes de trabalho e vida dos envolvidos. Dessa forma, o desenvolvimento dos empreendimentos não termina como um fim em si, mas serve também como ferramenta experimental para a construção participativa de conhecimentos que se estabelecem e podem ser difundidos.

Segundo Addor e Laricchia (2018), esses objetivos se coadunam com o papel da universidade de construir conhecimento e desenvolver soluções que possam ser úteis para além de casos pontuais. Para isso, entendem os autores que "essa estratégia articula os diferentes saberes o conhecimento acadêmico sistematizado com o conhecimento popular empírico - e gera soluçóes adequadas ao contexto trabalhado e às características sociais, econômicas e culturais dos trabalhadores" (Addor e Laricchia, 2018, p. 15). 
Um dos formatos metodológicos que tem ganhado bastante notoriedade na conexão entre extensão universitária e economia solidária refere-se às chamadas incubadoras tecnológicas de cooperativas populares (ITCPs), que envolvem grupos institucionalizados dentro das universidades que estruturam suas práticas a partir de uma sequência de atividades e instrumentos para o desenvolvimento de empreendimentos coletivos em suas diversas necessidades organizacionais e econômicas. Sob essa perspectiva, a incubação é concebida como um processo prático-educativo de acompanhamento sistêmico desses empreendimentos para auxiliar no enfrentamento de desafios que requerem conhecimentos técnicos específicos relacionados às atividades de gestão, produção e inserção em arranjos e cadeias produtivas locais, sobretudo no tocante à organização do trabalho cooperativo (Perissé et al., 2017; Leal, 2018).

Portanto, a atividade extensionista dos institutos de educação superior no Brasil se desdobra em um leque ampliado de açóes possíveis, mediadas pelas necessidades concretas das populaçóes presentes em seus territórios de incidência. Nesse contexto de pandemia, bem como dos riscos sociais a ele vinculados, a extensáo universitária surge, entáo, como um canal viável de enfrentamento dos impactos, sobretudo com a orientação principiológica da economia solidária para a mobilizaçáo de coletivos locais voltados à geraçáo de trabalho e renda e desenvolvimento territorial.

\section{PROJETOS EM CURSO}

Nesta seção, são apresentados, ainda que de forma panorâmica, os principais aspectos de três projetos aqui relatados que envolvem a prática da extensáo universitária com os princípios de economia solidária para favorecer grupos populacionais em situação de vulnerabilidade. Eles foram escolhidos por envolverem distintas configuraçóes institucionais de educação superior uma universidade federal, um instituto tecnológico federal e uma universidade estadual - e situarem-se em regióes distintas - Centro-Oeste, Nordeste e Sudeste -, além de compreenderem estratégias diferenciadas de intervenção no território, diretamente relacionadas aos desafios surgidos no contexto atual de pandemia.

Os projetos são:

- Programa Redes de Comercialização Solidária/UFMT;

- Programa IFPB Solidário/IFPB; e

- Núcleo de Extensão e Pesquisa em Economia Solidária, Criativa e Cidadania/Unesp.

\subsection{Programa Redes de Comercialização Solidária/UFMT}

O Programa Rede de Cooperação Solidária de Mato Grosso (Recoopsol) é uma ação de extensão e pesquisa multidisciplinar da UFMT em parceria com o movimento estadual de economia solidária. O programa é desenvolvido por docentes e discentes dos cursos de administração, agronomia, ciência da computação, ciências sociais, comunicação, contabilidade, economia, ciência e tecnologia de alimentos, engenharia florestal, filosofia, geografia, história, jornalismo e psicologia. Foi elaborado ainda em 2013 e está em execução 
desde 2015, trazendo como proposta central a criação, a ampliação e o fortalecimento de instâncias de economia solidária e redes de cooperação com foco na comercialização de produtos da agricultura familiar camponesa com origem da produção em comunidades tradicionais e famílias assentadas da reforma agrária.

Nesse sentido, o Recoopsol está estreitamente articulado com os movimentos de economia solidária e agricultura familiar em três regióes do estado de Mato Grosso: Baixada Cuiabana, Regiấo do Alto Paraguai e Regional Sul. A ligação se dá pela ativa participação das equipes e dos movimentos no Fórum Territorial de Segurança Alimentar e Nutricional da Baixada Cuiabana (FTSAN) e pelos fóruns de economia solidária das regiōes Sul e do Alto Paraguai.

A execução do Recoopsol se dá por meio de projetos de pesquisa e de extensão, ${ }^{17}$ dentre os quais está o projeto de Avaliação dos Processos de Gerenciamento da Central da Baixada Cuiabana com Enfoque nos Princípios das Redes de Colaboraçáo Solidária, que tinha como tarefa para 2020 mapear custos e levantar aportes necessários à logística da comercialização de três redes para o Programa Nacional de Alimentação Escolar (PNAE). Foram realizados encontros presenciais nos meses de janeiro e fevereiro com as três redes que têm contratos com o PNAE na Baixada Cuiabana, descritas a seguir.

1) Cooperativa Verde Vitória (CooperVV) e Cooperativa Mista dos Produtores Rurais de Poconé Ltda. (Comprup). A atividade principal se baseia no plantio de hortaliças orgânicas e na produção de insumos orgânicos provenientes da compostagem de resíduos orgânicos originários de supermercados, restaurantes e hotéis.

2) Centro de Tecnologias Alternativas (CTA), líder de uma rede territorial que atua desde o munícipio de Comodoro (distante $656 \mathrm{~km}$ de Cuiabá), passando por Pontes e Lacerda, Mirassol do Oeste e Cáceres. Desenvolve o projeto Rota Caminhos da Agroecologia, com a produçáo e a comercialização de produtos agroecológicos de origens diversas, como legumes, frutas e verduras; e produtos processados, como polpas, biscoitos e pães.

3) Cooperativa de Agricultores e Agricultoras Familiares de Nossa Senhora do Livramento - Coopernossasenhora (MT), que agrega várias comunidades tradicionais e famílias assentadas, e Cooperativa dos Pescadores e Artesãos de Pai André e Bonsucesso (Coorimbatá). Comercializa um mix de frutas, verduras, legumes, melado e laticínios da agricultura familiar e de origem convencional para garantir maior variedade.

Com a divulgação do primeiro caso de contaminação pelo Sars-COV-2 em Mato Grosso, no dia 16 de março de 2020, as aulas da rede pública foram suspensas, a partir do dia 23 de março, e, consequentemente, não houve mais pedidos do PNAE às cooperativas. Todas as redes estavam organizadas para atender à demanda do PNAE, mas a suspensão dos pedidos

17. Outros projetos são: Fóruns Territoriais - Instância de Articulação da Rede de Cooperação Solidária de Mato Grosso; Indicadores Socioambientais dos Empreendimentos Solidários articulados à Recoopsol; Transição agroecológica a partir de Sistemas Agroflorestais no Território da Baixada Cuiabana; Germinar - Curso de Formação de Lideranças Facilitadoras; Capacita Produtor; Software para dispositivos móveis na comercialização de produtos agrícolas; Promoção e proteção da saúde na Ecofeira: informação, alimentação e sustentabilidade; Seminário: Mulheres Indígenas, lutas, protagonismo e autonomia; Aplicação das análises de custos na produção orgânica: um experimento com os produtores orgânicos do Alto Pantanal mato-grossense; Inovação e Empreendedorismo: Juventudes, cooperativismo e trabalho colaborativo. 
acabou por derrubar a perspectiva de renda das comunidades tradicionais e famílias assentadas, com alto impacto na organização das cooperativas, em função da interrupção do fluxo de comercialização institucional. Assim, foi preciso buscar saídas para este momento de crise. A alternativa encontrada foi reforçar as iniciativas incidentes de comercialização direta, com entregas porta a porta, com uso de aplicativos de comunicação e de comercialização. Das três redes citadas, duas já realizavam vendas diretas e entregas com uso de aplicativos de mensagens instantâneas e mesmo um de comercialização via páginas on-line. A terceira, liderada pela Coopernossasenhora, iniciou a atividade já em meio à pandemia.

O programa Recoopsol, com aporte da equipe de comunicação, produziu um texto de divulgação para a rede liderada pelo CTA. Este texto foi adicionado às mídias sociais e aos canais de comunicação ativos pelo Recoopsol e ganhou razoável destaque, conseguindo, inclusive, pautar a mídia televisiva para produzir uma matéria sobre a inciativa. Em seguida, outro texto foi elaborado indicando as demais redes como alternativas para a aquisição dos produtos. Estas açóes ajudaram a ampliar as vendas e o alcance de clientes nas redes, logrando-se um aumento na demanda de todas as redes, conforme se segue.

1) CTA: ocorreu o acréscimo de $200 \%$ nos pedidos em Cuiabá e Várzea Grande.

2) COOPRVV: um crescimento de demanda, a ponto de garantir a venda de toda a produçáo disponível, reduzindo perdas.

3) Coopernossasenhora: crescimento de 35\% nos pedidos em Cuiabá e Várzea Grande, propiciando a ampliação da variedade de produtos oferecidos, com acréscimo de laticínios.

Outra ação do Recoopsol foi o apoio para o levantamento de custos das entregas para a definiçãao do preço a ser praticado. A próxima ação será a ampliação do mercado a partir da operaçáo de um aplicativo de venda para celular desenvolvido pela equipe de tecnologia da informação do programa.

Portanto, o distanciamento social provocado pela pandemia impôs aos empreendimentos econômicos solidários a necessidade de se adaptar ante os novos desafios. A forma democrática de gestão permitiu um processo rápido de consulta e decisão, respondendo às exigências de tomadas de decisóes emergenciais. Com estas novas frentes de comercialização, a ação extensionista se mostrou um elemento fundamental de apoio aos empreendimentos para, de um lado, garantir renda aos associados e, por outro, contribuir para manter as pessoas em casa, diminuindo o risco de proliferação do contágio da Covid-19 nos municípios atendidos.

\subsection{Programa IFPB Solidário/IFPB}

A atuação do IFPB no enfrentamento dos impactos negativos da atual pandemia vem ocorrendo em diferentes frentes de trabalho. Por meio do Edital do Conselho Nacional dos Institutos Federais (Conif) ñ 1/2020 - Enfrentamento à Covid-19, as instituiçóes foram convidadas a apresentar propostas de pesquisa e/ou extensão que possam apresentar, no curto prazo, soluçóes inovadoras para o desenvolvimento de produtos, serviços e processos para o enfrentamento emergencial à Covid-19. Após concorrência de âmbito nacional, o IFPB aprovou dois projetos, perfazendo 
um montante de aproximadamente $\mathrm{R} \$ 170$ mil. ${ }^{18}$ Ambos poderão ser instalados nos acessos aos hospitais e às unidades de pronto atendimento (UPAs), nas secretarias de saúde dos municípios, maternidades etc., com vistas à desinfecção de transeuntes, pessoas envolvidas com os equipamentos de saúde, médicos, enfermeiros e visitantes, entre outros, inclusive em portais de acesso aos nossos institutos federais.

Além dos projetos de pesquisa para o controle germicida, a atividade de extensão também foi mobilizada para o enfrentamento de necessidades emergenciais de famílias em situação de vulnerabilidade, viabilizadas por meio de termo de execução descentralizada (TED). ${ }^{19}$ No âmbito do IFPB, foi aprovada pelo Comitê de Enfrentamento à Covid-19, criado pela Portaria no ${ }^{\circ}$ 18/2020 Reitoria/IFPB, a campanha "IFPB Solidário". ${ }^{20}$ Ela resulta da ação de professores, gestores, servidores e estudantes pelos campi do instituto, além de contar com diversos parceiros, como prefeituras municipais e associações de trabalhadores locais que comungam do mesmo espírito dessa campanha, promovendo articulaçóes em torno da economia solidária e da educação popular pela prática extensionista. A campanha visa desenvolver diversas açóes que atendam a pessoas em situação de vulnerabilidade social, incluindo estudantes do próprio IFPB, imigrantes, pessoas em situação de rua, catadores de materiais recicláveis, população LGBTI, quilombolas, trabalhadores rurais e urbanos de baixa renda, entre outros. Para isso, são buscados recursos disponibilizados por editais de financiamento a vários tipos de projetos que convergem com essa proposta.

\title{
FIGURA 1
}

\section{Logo do IFPB Solidário}

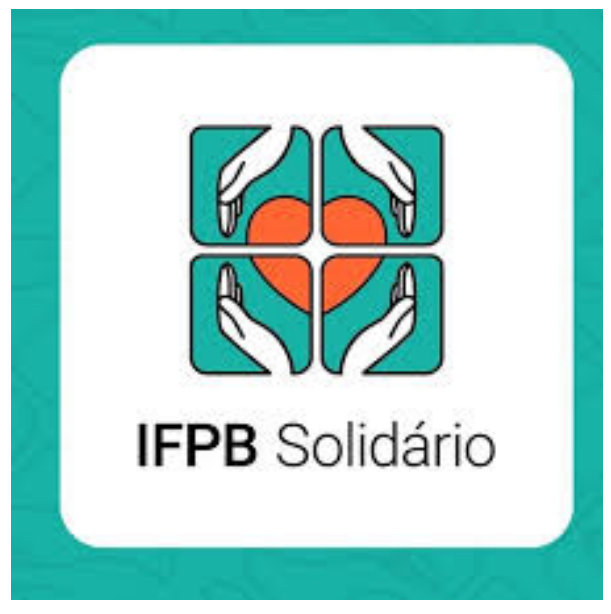

Fonte: IFPB Solidário.

\begin{abstract}
18. Os projetos são: i) UV-Corona - Equipamento Germicida UV-C Portátil: o objetivo deste projeto é construir e testar cinco protótipos do equipamento proposto, que possibilita emitir altas doses de luz ultravioleta UV-C, comprovadamente germicida, contribuindo para a desinfecção, prioritariamente, de objetos, superfícies e ambientes de hospitais que estão atuando no combate à pandemia; e ii) Spray Stop Coronavírus: um túnel de desinfecção, com medição de temperatura corpórea e autodiagnostico dos equipamentos.

19. O TED é um instrumento por meio do qual é ajustada a descentralização de crédito entre órgãos e/ou entidades integrantes dos Orçamentos Fiscal e da Seguridade Social da União, para execução de ações de interesse da unidade orçamentária descentralizadora e consecução do objeto previsto no programa de trabalho, respeitada fielmente a classificação funcional programática.
\end{abstract}

20. Site oficial da campanha: <https://www.ifpb.edu.br/ifpb-solidario>. 
Uma das açóes que compóem a campanha refere-se à formação de uma rede colaborativa de costureiras, que envolve alunas, monitoras e ex-alunas do curso de Formação Inicial e Continuada (FIC) de Costureira no campus de Pedras de Fogo, além de associaçóes de mulheres em vulnerabilidade social, como a Associação das Mulheres Águias de Pedras de Fogo e a Associação das Mulheres da Una de São José. Esse projeto também contou com o apoio das prefeituras dos municípios de Pedras de Fogo e de Juripiranga.

\section{FIGURA 2}

\section{Logo da Associação das Mulheres Águias de Pedras de Fogo}

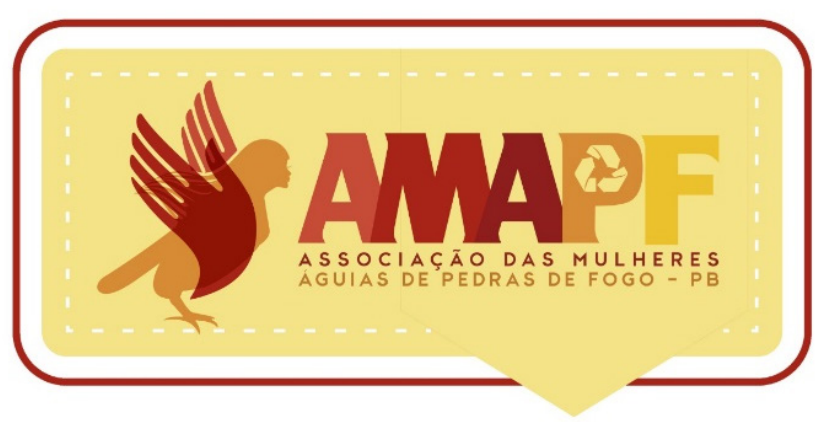

Fonte: IFPB Solidário.

\section{FIGURA 3}

\section{Logo da Associação das Mulheres da Una de São José}

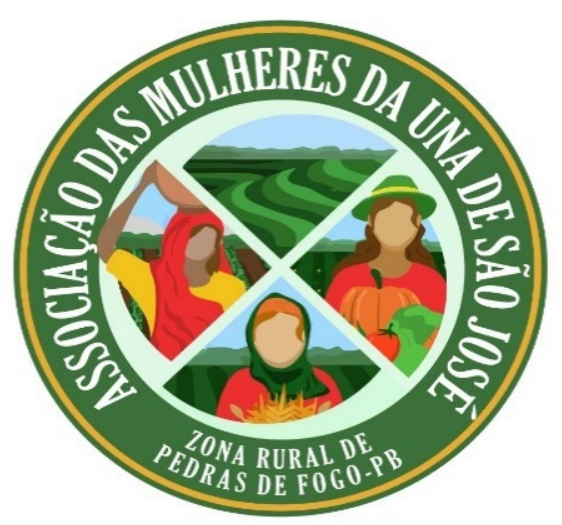

Fonte: IFPB Solidário.

O município de Pedras de Fogo, localizado na Mata Sul Paraibana, possui diversas associaçóes que comportam mulheres organizadas em núcleos urbanos e rurais para atividades coletivas nos setores de agricultura, artesanato e costura. Nesse momento crítico de pandemia, elas estão engajadas na produção de máscaras faciais de tecido para atender à demanda dos equipamentos de saúde e socioassistenciais dos municípios próximos, gerando renda para as famílias produtoras. ${ }^{21}$

21. Entre as parcerias e o TED o montante aproxima-se de $\mathrm{R} \$ 80$ mil. 
O campus Pedras de Fogo atua preferencialmente na logística desse projeto: recolhe o material (tecido de algodão, TNT, elástico, linha etc.), distribui às costureiras (preferencialmente àquelas ligadas às associaçôes) e realiza as entregas das máscaras após confeccionadas. Ademais, também contribui na negociação de parcerias com as prefeituras locais para a aquisição de quantidades determinadas de máscaras de tecido para suprir suas demandas. As prefeituras, por sua vez, remuneram as costureiras com o valor acertado da produção após a entrega dos produtos. ${ }^{22}$

Há também a demanda do próprio IFPB, adquirido via TED. A estimativa é que o projeto possibilite a aquisiçáo de aproximadamente 50 mil máscaras de tecido para a distribuição ao alunado, aos professores, aos técnicos administrativos e aos funcionários terceirizados do instituto em seus diferentes campi. Em uma segunda etapa, esse quantitativo de máscaras pode chegar a 120 mil unidades após o retorno às aulas presenciais, contribuindo também para a geração de trabalho e renda às famílias produtoras.

A comunidade acadêmica também foi mobilizada para uma campanha de arrecadação de doaçóes em dinheiro. Foram arrecadados cerca de R \$ 50 mil, o que permitiu adquirir 1.120 cestas básicas, distribuídas nos municípios de João Pessoa, Campina Grande, Sousa, Cabedelo, Patos, Guarabira, Esperança, Catolé do Rocha, Itaporanga, Princesa Isabel, Pedras de Fogo, Santa Luzia, Picuí e Soledade, beneficiando inúmeras pessoas em situação de vulnerabilidade social. Todas as cestas acompanham um kit de higienização, com sabonetes, água sanitária, álcool em gel e detergentes.

Vale ressaltar, por fim, que o IFPB vem desenvolvendo em sua estrutura multicampi uma série de outros projetos, dentre os quais estão: a produção de álcool em gel a $70 \%$ e álcool etílico glicerinado a $80 \%$ nos laboratórios (campus Cabedelo) para atender às necessidades dos serviços do Sistema Único de Saúde (SUS) e da população em geral; a criação de um aplicativo para análise de sintomas e auxílio no tratamento de doenças respiratórias; e a produção de máscaras de proteção facial (face shield) para os profissionais de saúde que estão na linha de frente do combate à Covid-19, produzidas pelo Polo de Inovação do IFPB em parceria com a rede do Núcleo de Tecnologias Estratégicas em Saúde (Nutes), da Universidade Estadual da Paraíba (UEPB) - para distribuição para as áreas de saúde do estado. ${ }^{23}$

\subsection{Nepesc/Unesp}

O Núcleo de Extensão e Pesquisa em Economia Solidária, Criativa e Cidadania (Nepesc), sediado na Faculdade de Ciências e Letras (FCL) da Unesp, campus Araraquara, em cooperação com a Coordenadoria de Trabalho e Economia Criativa e Solidária da Prefeitura Municipal de Araraquara, vem se empenhando em realizar açóes passíveis de mitigarem efeitos degradantes das condiçóes sociais e econômicas de vida de parcela da populaçáo mais vulnerável do município.

22. Ressalta-se que, como destacado por Valadares et al. (2020), alguns estados da região Nordeste têm desenvolvido programas de apoio a associações de costureiras, sobretudo em áreas rurais, para a fabricação de máscaras a serem utilizadas nas redes municipais e estaduais de saúde, como forma de geração de renda a famílias em situação de vulnerabilidade.

23. Já foram construídas e distribuídas mais de 1,2 mil máscaras para unidades de saúde em todo o estado da Paraíba, somando mais de $R \$ 80$ mil em investimentos. 
Nessa perspectiva, duas frentes de intervenção foram priorizadas: o apoio à produção de alimentos e de máscaras. No campo da produção de alimentos, as açóes vêm sendo realizadas em parceria com a Associação Horta Comunitária da Zona Norte (sediada no Residencial Valle Verde), tendo como principal inovação, desde o advento da pandemia, a criação e a disseminação do movimento “Terra Solidária - por mais quintais produtivos”. ${ }^{24}$ Já são mais de trinta hortas criadas, em quintais de residências, em escolas, na Moradia Estudantil, em Araraquara, Matáo e Américo Brasiliense, que contaram, como parte dos recursos para a sua implantação, com valores oriundos do Conselho Nacional de Desenvolvimento Científico e Tecnológico (CNPq), por meio do projeto Corredor Verde Agroflorestal.

No âmbito da confecção de máscaras, a FCL vem prestando apoio à Coordenadoria de Trabalho e Economia Criativa e Solidária da Prefeitura Municipal de Araraquara, que abriu as dependências do Espaço Kaparaó ${ }^{25}$ para que um grupo de mulheres vinculado à Associação Máos que Criam passasse a produzir máscaras de pano, como forma de contribuir para a proteção da população e para a geraçáo de renda. A associação é composta, majoritariamente, por mulheres artesãs, com experiência na prática têxtil, que mantêm o desejo comum de se desenvolver como empreendimento autônomo.

Além dessas açóes, expressóes concretas da práxis extensionista do Nepesc, o núcleo vem realizando um amplo mapeamento dos demais empreendimentos solidários existentes em Araraquara e regiáo, com vistas à identificação de suas respectivas fragilidades e possibilidades de superação, de modo a assegurar a geração de renda.

Complementam essas ações, as atividades permanentes e regulares de mobilização e de formação de estudantes. Reunióes semanais vêm sendo realizadas, com a participação regular de cerca de trinta estudantes, seja para debater e organizar as açóes do núcleo, seja para a oferta de um curso de extensão em formação de agentes de incubaçáo de empreendimentos solidários, seja ainda para a participaçáo em uma programaçáo de conferências e debates com convidados externos e docentes do núcleo.

\section{CONSIDERAÇÕES FINAIS}

A humanidade vem enfrentando, nos últimos meses, uma das maiores crises da história, provocada pela pandemia da Covid-19. Muito mais do que uma ameaça à saúde individual das pessoas, ela tem desafiado a capacidade dos países de apresentarem respostas efetivas e rápidas em defesa da vida em sociedade e da garantia de direitos fundamentais à toda a população.

Nesse contexto, as instituiçôes de ensino superior podem contribuir, em diversas frentes, no enfrentamento de tais desafios. Além da capacidade de pesquisa para a geraçáo de produtos que auxiliem diretamente no combate e no controle da proliferação viral, a atividade extensionista de apoio à geração de trabalho e renda e o atendimento a demandas emergências nos territórios em que as instituiçóes se encontram inseridas surge, então, como uma importante possibilidade de açáo.

24. Disponível em: <https://bit.ly/3g7GVaD>.

25. Disponível em: <https://bit.ly/2A6V7RX>. 
Neste texto, foram apresentadas três experiências que abordam distintas possibilidades concretas de atuação nessa perspectiva, com a mobilização de grupos produtivos associativos para o atendimento de demandas que surgem da própria dinâmica de combate à epidemia, como a necessidade massiva de máscaras e a comercialização domiciliar de alimentos em razão da medida protetiva de isolamento social. Tais atividades também são conectadas com o atendimento de outras necessidades emergenciais dessas populaçôes, além de servirem como catalisadoras de parcerias com os poderes públicos locais e organizaçóes privadas em geral.

O objetivo aqui traçado foi lançar luz sobre essas experiências em curso, mostrando a diversidade de possibilidades de interação com os territórios e as demandas concretas que podem ser atendidas a partir das capacidades instaladas dessas instituiçóes. Não existe uma forma padronizada, concebida como algo passível de uniformizaçáo, independentemente dos seus contextos de ação. Os desafios metodológicos são imensos, sobretudo quando se envolvem temáticas complexas como a formação de dinâmicas locais de solidariedade, autogestáo e acesso à alimentação saudável.

Como as três experiências relatadas encontram-se em início de atividade, é necessário que novas sistematizaçôes posteriores problematizem de forma mais aprofundada suas práticas, suas metodologias de intervenção, seus resultados alcançados, seus limites e suas potencialidades, de modo a subsidiar novas abordagens na relação entre extensão universitária e economia solidária no Brasil.

\section{REFERÊNCIAS}

ADDOR, F.; LARICCHIA, C. R. (Orgs.). Incubadoras tecnológicas de economia solidária. Rio de Janeiro: Editora da UFRJ, 2018.

AMITRANO, C. et al. Medidas de enfrentamento dos efeitos econômicos da pandemia Covid-19. Brasília: Ipea, 2020. (Texto para Discussão, n. 2559).

CULTI, M. N. Incubadora tecnológica de empreendimentos econômicos solidários: aspectos conceituais e a práxis do processo de incubação. Maringá: UEM, 2011.

DWECK, E. et al. Impactos macroeconômicos e setoriais da Covid-19 no Brasil. Rio de Janeiro: UFRJ, 2020. (Nota Técnica).

LEAL, L. P. Princípios e fundamentos para uma tipologia de incubação tecnológica em economia solidária. In: ADDOR, F.; LARICCHIA, C. R. (Orgs.). Incubadoras tecnológicas de economia solidária. Rio de Janeiro: Editora da UFRJ, 2018.

NOGUEIRA, M. O.; SILVA, S. P.; CARVALHO, S. S. Socorro governamental às pequenas unidades produtivas frente à atual pandemia. Brasília: Ipea, 2020. (Nota Técnica, n. 63) .

PAlLUDETO, A. W. et al. Política econômica em tempos de pandemia: experiências internacionais selecionadas. Campinas: Unicamp, 2020. (Série Laboratório de Economia Internacional, n. 1).

PERISSÉ, C. et al. A avaliação do Proninc 2017: metodologia e resultados. Mercado de Trabalho: conjuntura e análise, Brasília, n. 63, 2017. 
SILVA, S. P. Análise das dimensóes socioestruturais dos empreendimentos de economia solidária no Brasil. Brasília: Ipea, 2017. (Texto para Discussão, n. 2271).

VALADARES, A. A et al. Agricultura familiar e abastecimento alimentar no contexto do Covid-19:

uma abordagem das açóes públicas emergenciais. Brasília: Ipea, 2020. (Nota Técnica, n. 69). 